\title{
Internet como fonte de vantagem competitiva: um caso na indústria portuária
}

\author{
Claudio Luis Cruz de Oliveira EPUSP \\ Fernando José Barbin Laurindo EPUSP \\ Marly Monteiro de Carvalho EPUSP \\ Francisco de Vilhena Moraes Silva Agência NBS
}

\section{RESUMO}

A Internet tem sido reconhecida como uma fonte de vantagem competitiva. Em países emergentes, como o Brasil, a Internet representa novas possibilidades para empresas e para inserção da economia nacional em mercados globais. A presente pesquisa objetiva entender como uma empresa atuando no setor portuário no Brasil pode obter vantagens competitivas através de aplicações baseadas em Internet. Para isto, algumas questões devem ser respondidas: (i) Como uma empresa brasileira pode usar aplicações baseadas em Internet para estabelecer diferenciais frente à concorrência no setor portuário? (ii) Como as características do cenário brasileiro - instabilidade econômica, legislação, impostos, mão-de-obra, criatividade - afetaram as estratégias de aplicações on-line baseadas em Internet dessa empresa? Para tanto, foram utilizados diversos elementos presentes na bibliografia sobre estratégia e tecnologia da informação. 0 método aplicado foi o estudo de caso, realizado em um terminal de contêineres do Porto de Santos que tem usado intensamente a Internet em suas operações.

\section{Internet as source of competitive advantage: a case in the port industry}

\begin{abstract}
Internet has been acknowledged as a source of competitive advantage. For development countries as Brazil, the Net can bring new possibilities for companies and for national economy insertion in global markets. For this reason, Internet strategic use was analysed in a Brazilian Port. This research aims to understand how a company of the ports industry in Brazil can obtain competitive advantages through Internet-based applications. For this purpose, the following questions should be answered: (i) How a Brazilian company can use Internet-based applications to establish differentials from its competitors in ports industry? (ii) How the characteristics of the Brazilian environment like economic instability, laws, taxes, workforce, creativity biased on-line strategies of this company? In order to clarify these points, concepts about strategy and information technology were analysed. The applied method was case study, performed in a container terminal in the Brazilian Port in Santos, which had used Internet intensively in its operations.
\end{abstract}

\section{KEY WORDS}

Internet, logistics, value system, e-business 


\section{INTRODUÇÃO}

A Internet trouxe impactos profundos na estrutura de algumas indústrias, principalmente naquelas com altos custos de comunicação, aquisição de informações ou rastreamento de transações. A Internet melhora a eficiência operacional de corporações reduzindo seus custos transacionais (RAYPORT; SVIOKLA, 1995). Por outro lado, os ganhos de eficiência obtidos com a Internet não são suficientes para desenvolver uma estratégia competitiva, considerando que outras empresas podem facilmente copiar as aplicações baseadas nessa tecnologia de plataforma aberta e com protocolos padrão. Por conseqüência, as empresas devem procurar uma forma de utilizar as operações na Internet para desenvolverem um posicionamento estratégico inovador que possa possibilitar vantagens competitivas e assim possibilitar um prêmio em preço (PORTER, 2001).

\section{Novas estruturas organizacionais e de inter-relação entre as empresas foram criadas ou viabilizadas}

\section{com o crescente uso da TI.}

Neste artigo, o impacto da Internet na estrutura da indústria será analisado através dos conceitos de análise estrutural da indústria (PORTER; 2001 e 1979) e de cadeia de valor (PORTER; MILLAR, 1985). O modelo da cadeia de valor virtual descrito por Rayport e Sviokla (1995) será também usado para entender como a tecnologia da informação permite a integração virtual na indústria e o desenvolvimento de novos negócios no marketspace. Finalmente, o conceito de redes de valor (BOVET; MARTHA, 2001) será utilizado para especificar aplicações on-line baseadas na estratégia de negócios.

Com base nestes conceitos, este estudo pretende contribuir para um melhor entendimento de como ocorre a relação entre a estratégia de tecnologia da informação (TI) e seu impacto na melhoria da eficiência na indústria portuária. Parte-se do pressuposto de que este tipo de aplicação pode gerar ganhos administrativos como facilidade de procura por serviços, diminuição de custos de atendimento ao cliente e melhores decisões baseadas em conhecimento adicional sobre os agentes de todo o sistema de valor (CARVALHO et al., 2003; LAURINDO et al., 2003).

A abordagem de estudo de caso foi adotada para a obtenção de uma base empírica para este artigo (YIN, 1991; CLAVER et al. 2000). Com base na importância do uso da Internet no setor de atuação e na empresa, um operador portuário foi escolhido como foco de pesquisa pelos autores.
Operadores portuários são empresas que oferecem múltiplos serviços nos terminais portuários, como carga, descarga, e armazenamento. O terminal portuário é o local físico onde as mercadorias são transferidas para os navios e também onde as cargas são desembarcadas. Note-se que uma primeira versão deste estudo, contendo resultados preliminares e parciais, foi publicada no Euroma em 2003 (OLIVEIRA et al., 2003)

As informações foram obtidas através de entrevistas semi-estruturadas que focaram na análise detalhada dos objetivos de negócios e nos processos do operador portuário estudado.

Considera-se, com base nos resultados da primeira etapa do estudo, que ganhos administrativos advindos da aplicação da Internet são esperados na indústria portuária (OLIVEIRA et al., 2003). Nesta segunda etapa do estudo, busca-se comprovar se houve obtenção de vantagem competitiva com essa aplicação. Para tanto, adotaramse referências sobre o impacto estratégico da TI, como os fatores críticos de sucesso (ROCKART, 1979), grid estratégico (MCFARLAN,1984) e alinhamento estratégico (HENDERSON; VENKATRAMAN, 1993). Houve ainda a inclusão de indicadores para mostrar se a empresa obteve vantagens competitivas com a Internet, incluindo dados quantitativos e tabela comparativa da presença on-line da empresa versus a dos concorrentes. Para tanto, em relação à primeira etapa do estudo, realizaram-se novas entrevistas e acrescentaram-se dados de campo para detalhar as aplicações de tecnologia e avaliar se, de fato, elas geraram vantagens frente à concorrência.

\section{A INTERNET: FERRAMENTA PODEROSA PARA DESENVOLVIMENTO ESTRATÉGICO}

\subsection{A revolução das informações}

A TI está transformando a natureza dos produtos, processos, empresas, indústrias e até mesmo a própria competição (PORTER; MILLAR, 1985). Novas estruturas organizacionais e de inter-relação entre as empresas foram criadas ou viabilizadas com o crescente uso da TI, principalmente após a disseminação do uso comercial da Internet (CARVALHO; LAURINDO, 2003; LAURINDO, 2002). Os sistemas de informação organizacional evoluíram em quatro eras consecutivas (ZWASS, 1998): (i) suporte operacional; (ii) suporte à administração e trabalhos de conhecimento; (iii) suporte de transformação de negócios e competição; (iv) computação onipresente. O principal objetivo desta última 
era é a integração eletrônica de toda a organização. Essa integração impulsionou o desenvolvimento de novos produtos, serviços, processos e até de novos negócios (FARRELL, 2003; TAPSCOTT, 2001; PORTER; MILLAR, 1985).

Esses sistemas também administram interações cada vez mais complexas dentro da empresa e na "organização estendida" consistindo da empresa, seus parceiros de negócio, consumidores e fornecedores (MATTOS; LAURINDO, 2007). Este último tipo de sistema de informações, de caráter estratégico, será analisado nesse artigo.

\subsection{Impactos da Tecnologia da Informação na natureza da competição}

A fim de destacar o papel da TI na competição, Porter e Millar (1985:150) exploraram o conceito de "cadeias de valor" (Figura 1): "A cadeia de valor da empresa é um sistema de atividades interdependentes, que são conectadas por ligações. Ligações existem quando a forma em que uma atividade é desempenhada afeta o custo ou efetividade de outras atividades. A administração cautelosa das ligações é também uma poderosa fonte de vantagem competitiva devido à dificuldade que os concorrentes têm em percebê-las e em resolver trade-offs entre as linhas organizacionais".

A maior corrente de atividades incluindo a cadeia de valor dos fornecedores, da empresa e de seus canais é denominada "sistema de valor" (Figura 2). As ligações conectam atividades de valor dentro da empresa assim como criam interdependências entre essa cadeia e as cadeias dos fornecedores e canais.

Esses mesmos autores destacaram os efeitos da TI na cadeia de valor: (i) a tecnologia está transformando a forma como as atividades de valor são desempenhadas e a natureza das ligações entre elas; (ii) ela está afetando o escopo da competição; (iii) ela também está remodelando a forma como produtos suprem as necessidades dos usuários. A importância da tecnologia na empresa é grande em indústrias como bancos, jornais e linhas aéreas, que têm muita informação agregada a produtos e serviços. Estas indústrias de informação intensiva foram as primeiras usuárias do processamento de dados. O operador portuário analisado no estudo de caso pode ser considerado uma empresa de informação intensiva devido ao rastreamento da carga, aos procedimentos alfandegários, às informações de cuidados de armazenamento e à definição de rotas de transporte.

Porter e Millar (1985) analisaram os efeitos da TI na natureza da competição. Eles identificaram três formas específicas em que a tecnologia afeta a competição: (i) ela altera a estrutura da indústria, pois tem a capacidade de influenciar cada uma das cinco forças (PORTER 1979); (ii) ela suporta estratégias com foco em diferenciação e estratégias com ênfase em custos; (iii) ela cria negócios inteiramente novos.

Tanto as aplicações de $e$-commerce como as de $e$-business se destacam como aplicações estratégicas de TI (PORTER, 2001; EVANS; WUSTER, 1997). Porter (2001) considerou a Internet como a melhor plataforma de TI para criar um posicionamento estratégico único porque sua arquitetura e padrões tornam possível criar sistemas realmente integrados e customizados que reforçam a integração entre as atividades.

Nas empresas baseadas em conhecimento, o papel da Internet pode ser ainda mais relevante, uma vez que as ati-

\begin{tabular}{|c|c|c|c|c|c|c|c|}
\hline \multirow[t]{5}{*}{ Atividades - Meio } & $\begin{array}{c}\text { Infra-estrutura } \\
\text { empresarial }\end{array}$ & & & & & & \\
\hline & $\begin{array}{l}\text { Gerenciamento de } \\
\text { recursos humanos }\end{array}$ & & & & & & \\
\hline & $\begin{array}{l}\text { Desenvolvimento de } \\
\text { tecnologias }\end{array}$ & & & & & & \\
\hline & $\begin{array}{l}\text { Aquisição de } \\
\text { insumos }\end{array}$ & & & & & & \\
\hline & & $\begin{array}{l}\text { Logística } \\
\text { interna }\end{array}$ & Operações & $\begin{array}{l}\text { Logística } \\
\text { externa }\end{array}$ & $\begin{array}{l}\text { Marketing e } \\
\text { vendas }\end{array}$ & $\begin{array}{l}\text { Prestação de } \\
\text { serviços }\end{array}$ & Margem \\
\hline
\end{tabular}

Figura 1: A cadeia de valor

Fonte: Porter; Millar, 1985. 
vidades não seguem um fluxo rígido como o apresentado na cadeia de valor tradicional (Figura 1) e os sistemas de informação são parte das competências essenciais para o sucesso do negócio (DUHAN et al., 2001).

Prahalad e Ramaswamy (2000) destacam o fortalecimento do papel do cliente com as novas tecnologias, sendo ele um co-participante no desenvolvimento de produtos. Tapscott (2001), uma das referências mais enfáticas na defesa do conceito de Nova Economia, chega a defender que, no futuro, os gestores analisarão a proposta de valor dos clientes, desenharão as atividades necessárias para realizar a proposta e delegarão as mesmas para parceiros Web. Convém dizer que a afirmação deste autor pode ter sido enviesada, devido à empolgação reinante sobre as aplicações da Internet nos negócios. Contudo, Farrell (2003), em uma análise realizada em um momento posterior à euforia da Internet, defendeu que o uso da TI associado a mudanças nos processos das empresas trouxe ganhos importantes.
Para estes autores, a cadeia de valor tradicional (definida conforme a visão de PORTER; MILLAR, 1985) trata a informação como um elemento de suporte ao processo de adição de valor, não como uma fonte de valor. Os administradores de empresa enxergam muito mais possibilidades para criação e extração de valor pensando em termos de cadeia de valor virtual e cadeia de valor física do que eles poderiam considerando exclusivamente a cadeia de valor tradicional. Por exemplo, a Federal Express criou valor para seus consumidores permitindo que eles rastreassem suas encomendas através do website da Fedex na Internet.

$\mathrm{O}$ marketspace promove a integração virtual dos agentes da indústria (RAYPORT; SVIOKLA, 1995). Como integração virtual, entende-se a promoção das "ligações" da cadeia de valor descritas por Porter e Millar (1985), através de meios eletrônicos (CHANDRASHEKAR; SCHARY, 1999). Em mercados como o de economias nacionais emergentes sem uma infra-estrutura física adequada conectando os agentes, uma plataforma virtual pode ser criada em primeiro lugar. Por exemplo, a Companhia de Internet Chinesa desenvolveu uma rede de sites na Internet para quarenta cidades industriais. A rede proporciona documentos multimídia que descrevem uma ampla rede de produtos, um catálogo completo de leis chinesas sobre exportação e comércio, um serviço de tradução e notícias. Esses serviços e informações não estavam disponíveis antes porque os chineses não tinham uma infra-estrutura física adequada.

\subsection{Redes de valor}

O conceito de redes de valor (BOVET; MARTHA, 2001) foi usado para explorar as oportunidades do marketspace com a finalidade de desenvolver um posicionamento estratégico único na indústria portuária. A rede de valor foi escolhimesmos consumidores no marketspace.

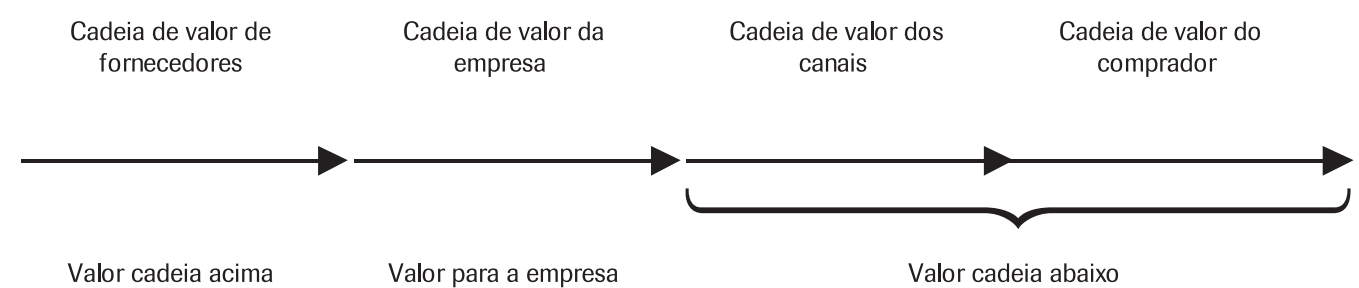

Figura 2: 0 sistema de valor

Fonte: Porter; Millar, 1985. 
da como o modelo para o estudo de caso devido a três fatores: (i) a capacidade de suportar os conceitos de marketspace, pois ele é baseado numa rede flexível (Figura 3); (ii) a possibilidade de transformar estratégias de alto nível em propostas de valor específicas entregues como aplicações de Internet; (iii) o modelo foi desenvolvido usando uma base empírica baseada numa pesquisa incluindo empresas relevantes como Cisco Systems, Ford, Intel, Li \& Fung e IBM.

\subsection{Avaliação da TI nas organizações}

A fim de avaliar o impacto da TI na organização, serão analisados os seguintes modelos: fatores críticos de sucesso (ROCKART, 1979), grid estratégico (MCFARLAN, 1984) e alinhamento estratégico (HENDERSON; VENKATRAMAN, 1993). Esses modelos serão úteis na confecção de um quadro de análises para os estudos de caso (PEREIRA; LAURINDO, 2007).

O grid estratégico proposto por McFarlan (1984) permite analisar o impacto atual e futuro das aplicações de TI no negócio da empresa considerando quatro quadrantes (Figura 4) (LAURINDO, 2005; MCFARLAN, 1984):

- Suporte: pequena importância da TI nas estratégias atual e futura
- Fábrica: aplicações de TI existentes contribuem para o sucesso da empresa, mas não há previsão de novas aplicações com impacto estratégico

- Transição: a TI passa de suporte para uma posição mais estratégica

- Estratégico: as aplicações atuais e futuras são estratégicas e afetam o negócio da empresa

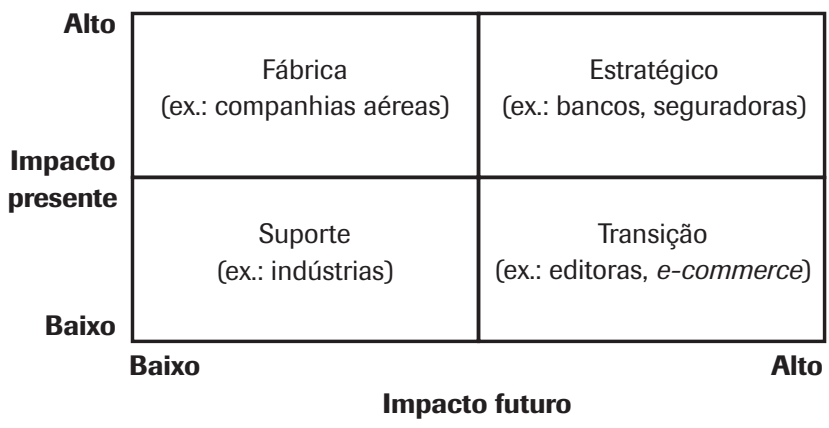

Figura 4: Impactos das aplicações de TI

Fonte: adaptado de Laurindo 2001; McFarlan, 1984.

Para fornecer uma visão integrada e concisa dos indi-

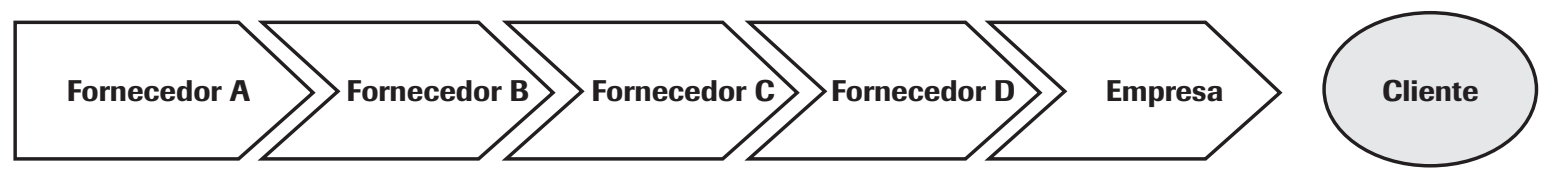

\begin{tabular}{|l|l|l|}
\hline \multicolumn{1}{|c|}{ Cadeia de Valor Tradicional } & \multicolumn{1}{c|}{ Rede de Valor } \\
\hline $\begin{array}{l}\text { Único formato para qualquer } \\
\text { finalidade }\end{array}$ & Alinhada com o cliente \\
\hline Rígida, inflexível & Ágil, flexível \\
\hline Independente e seqüencial & Colaborativa e sistemática \\
\hline Analógica & Digital \\
\hline
\end{tabular}

Notas:

1 - Tamanho da esfera representa tamanho de cada agente através de um indicador, por exemplo, faturamento

2 - Linhas representam relações entre os agentes, sejam comerciais ou de troca de informações

Figura 3: Cadeia de valor versus rede de valor

Fonte: Adaptado de Bovet e Martha, 2001. 
cadores de desempenho aos executivos, Rockart (1979) propôs uma nova abordagem para a concepção dos sistemas de informação gerenciais (SIG). Os fatores críticos de sucesso (FCS) são o foco da abordagem proposta, uma vez que representam "o número limitado de áreas nas quais os resultados, se satisfatórios, asseguram o desempenho competitivo bem-sucedido para a organização" (ROCKART, 1979). Este autor sugere os seguintes passos para implementação dos FCS.

- Análise do ramo de atuação da empresa

- Identificação dos FCSs

- Definição de medidas dos FCSs

- Definição de sistemas de informação para controle dessas medidas

Henderson e Venkatraman (1993) propuseram um modelo para analisar a importância estratégica do papel da TI nas empresas, modelo esse que trouxe uma inovação ao considerar a possibilidade de a estratégia de TI poder mudar a estratégia de negócios. Os referidos autores apresentaram quatro perspectivas principais de alinhamento estratégico (Figura 5):

- Execução da estratégia - a estratégia de TI derivaria da estrutura de negócios. É o modelo mais difundido entre as empresas. Os critérios de desempenho para utilização da TI são predominantemente financeiros.

- Transformação tecnológica - a estrutura de TI não é restrita à estrutura de negócios da empresa. O critério de desempenho é baseado em liderança tecnológica.

- Potencial competitivo - a definição da estratégia de negócios provém da nova estratégia de TI adotada. Essa perspectiva visa à liderança de negócios.

- Nível de serviço - a criação de uma organização classe mundial em serviços de sistemas de informação é o objetivo desta perspectiva. O critério de desempenho baseia-se na satisfação do cliente.

\section{MÉTODO DA PESQUISA}

\subsection{Abordagem qualitativa: estudo de caso}

Diante da questão a ser investigada, isto é, como ocorre a relação entre a TI e seu impacto na melhoria da eficiência na indústria portuária (apresentada no item 1), a abordagem de estudo de caso será utilizada para prover uma base empírica para o estudo. Esta abordagem é bastante difundida nos estudos de TI, representado 31\% dos estudos empíricos

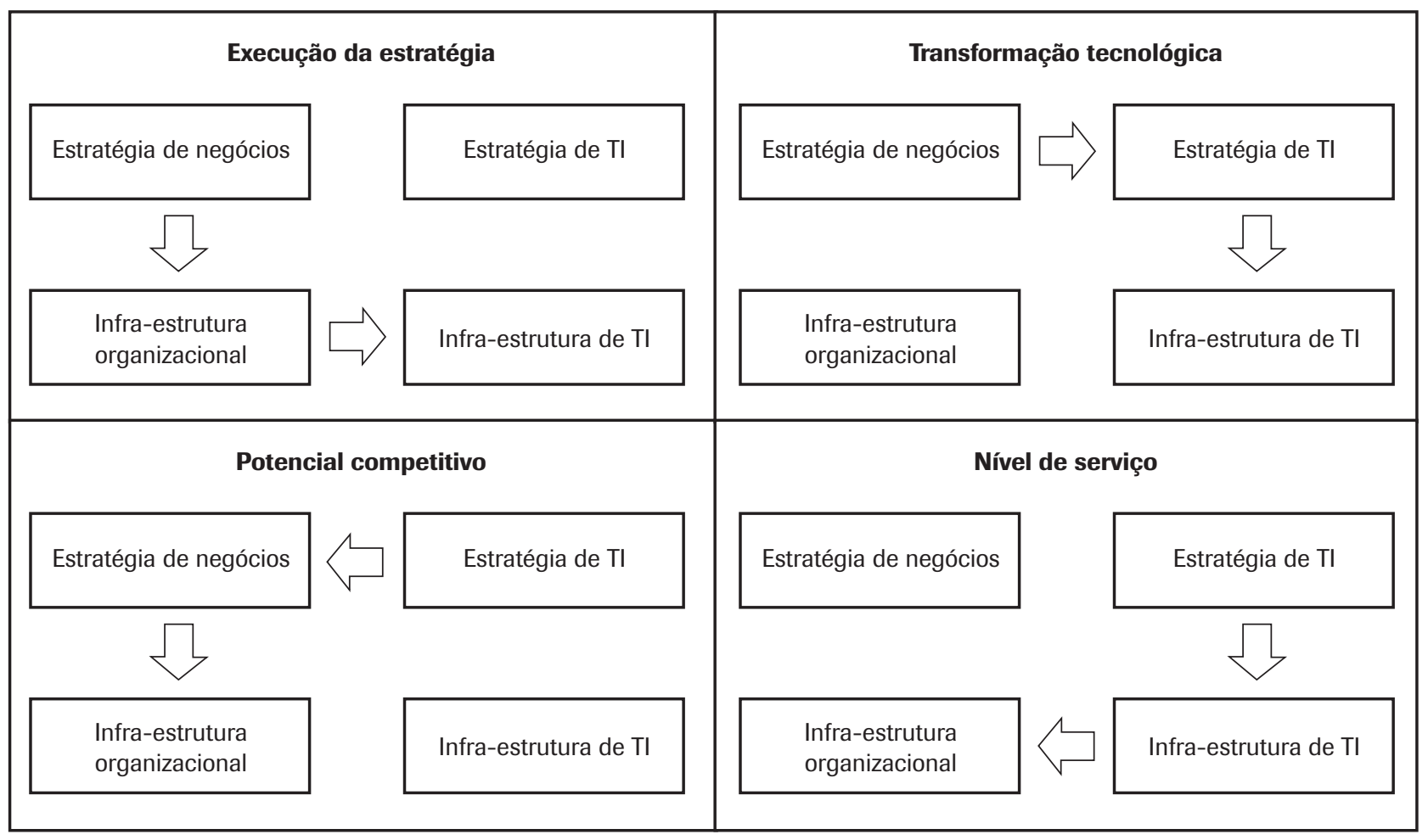

Figura 5: Perspectivas do alinhamento estratégico

Fonte: Adaptado de Henderson; Venkatraman, 1993. 
publicados nesta área (CLAVER, 2000). Segundo Benbasat et al. (1987), o uso do estudo de caso no contexto da TI possui as seguintes vantagens:

- O investigador pode estudar o sistema de informação no seu estado natural, aprendendo e gerando teorias com base nas práticas verificadas;

- Esse método leva o investigador a perceber a natureza e a complexidade do problema;

- É apropriado para áreas onde os estudos são poucos e recentes, portanto, adequado ao contexto da TI.

Serão aplicadas entrevistas semi-estruturadas baseadas num roteiro predefinido (YIN, 1991) bem como outras fontes de informação (MIGUEL, 2007). Como afirma Leonard-Barton (1990), um estudo de caso é uma história ou um fenômeno atual, retratado de múltiplas fontes de evidência, que pode incluir dados de observação direta e entrevistas sistemáticas bem como de arquivos públicos e privados. Qualquer fato relevante no contexto do fenômeno é um dado potencial no estudo de caso.

O primeiro passo para definir o escopo da pesquisa foi elencar as questões fundamentais a serem analisadas. Foram selecionados os seguintes questionamentos considerados cruciais para aprofundamento da análise na discussão.

- Como a empresa tem aproveitado o potencial de seus negócios na Internet?

- A empresa obteve vantagens competitivas com a Internet?

- Caso a empresa tenha gerado vantagem competitiva, como ela conseguiu obter diferenciais frente à concorrência?

- Como as características do cenário brasileiro afetaram as estratégias on-line dessa empresa?

A empresa selecionada para o estudo de caso é um terminal portuário do Porto de Santos, escolhida através dos critérios apresentados na Tabela 1.

\subsection{Roteiro das entrevistas}

Doze entrevistas foram realizadas com executivos da empresa cobrindo diferentes áreas: financeira, comercial, marketing, operações, qualidade e tecnologia. Para auxiliar no andamento das entrevistas, priorizar os pontos mais importantes da pesquisa e relacionar a revisão teórica ao estudo de caso, foi elaborado um roteiro que se encontra detalhado no anexo 1.

\section{ESTUDO DE CASO: TERMINAL DE CONTÊINERES DO PORTO DE SANTOS}

\subsection{Descrição do mercado}

A empresa analisada é um terminal de contêineres que opera no porto de Santos, principal porto brasileiro e latinoamericano. O valor movimentado nos domínios desse porto (US\$ 32,4 bilhões) é maior do que a soma dos outros quatro maiores portos nacionais (US\$ 31,1 bilhões) (Tabela 2) (PORTO DE SANTOS, 2005a).

\section{Tabela 2: Movimentação dos cinco principais portos} nacionais em 2003.

\begin{tabular}{cc}
\hline Porto & $\begin{array}{c}\text { Valor movimentado free on board (FOB) } \\
\text { em bilhões US\$̦ }\end{array}$ \\
\hline Santos & 32,4 \\
Vitória & 9,2 \\
Paranaguá & 8,8 \\
Rio Grande & 7,4 \\
Rio de Janeiro & 5,7 \\
\hline
\end{tabular}

Fonte: Adaptado de Porto de Santos, 2005a.

O porto de Santos contribui expressivamente para o comércio exterior brasileiro. Em 2004, o valor movimentado nas exportações free on board (FOB), termo que indica que o vendedor pagará pelos custos de transporte até um ponto

Tabela 1: Critérios para seleção da empresa analisada no estudo de caso

\begin{tabular}{cl}
\hline Critério & \multicolumn{1}{c}{ Aplicação } \\
\hline $\begin{array}{c}\text { Relevância para } \\
\text { economia }\end{array}$ & $\begin{array}{l}\text { (i) o porto de Santos é responsável por 26\% da movimentação de carga no Brasil (A Tribuna, 2003:A12). } \\
\text { (ii) o setor portuário pode impulsionar a inserção do Brasil no comércio exterior. }\end{array}$ \\
$\begin{array}{c}\text { Uso intensivo da } \\
\text { informação }\end{array}$ & $\begin{array}{l}\text { Trata-se de empresa de informação intensiva graças ao rastreamento da carga, aos procedimentos } \\
\text { alfandegários, às informações de cuidados de armazenamento e à definição de rotas de transporte. }\end{array}$ \\
$\begin{array}{c}\text { Potencial da } \\
\text { Internet }\end{array}$ & $\begin{array}{l}\text { (i) A Internet pode otimizar processos logísticos altamente dependentes das informações geradas e da } \\
\text { agilidade de transmissão e entrega dessas informações. } \\
\text { (ii) O desenvolvimento de uma nova posição estratégica baseada nas aplicações on-line é bem-vindo para } \\
\text { uma indústria que não conecta os processos de seus vários agentes através da TI }\end{array}$ \\
\hline
\end{tabular}


específico e que deste ponto em diante o comprador será o responsável, foi de US $\$ 26,9$ bilhões, o que lhe garantiu uma participação de $27,9 \%$ nos US $\$ 96,5$ bilhões exportados pelo Brasil. As importações FOB por Santos em 2004 acumularam US\$ 16,0 bilhões, ou 25,5\% do total nacional de US\$ 62,8 bilhões (SOUZA, 2005).

Em 2004, o porto de Santos também movimentou cerca de 70 milhões de toneladas de cargas; a previsão para 2005 é chegar à série histórica dos 75 milhões (GAZETA MERCANTIL, 2005) (Figura 6). Trata-se de uma estimativa factível se levarem em consideração os crescimentos de $12 \%$ durante dois anos seguidos (PORTO DE SANTOS, 2005b).

Além da importância econômica, o porto de Santos faz parte da história do país. Apesar de o marco de fundação ser a inauguração do cais construído em 1892, o porto nasceu com a colonização do Brasil em 1532, durante expedição colonizadora de Martin Afonso de Souza. Foi dele a idéia de transferir o porto da baía de Santos para o interior do canal, em águas protegidas do vento e das ondas bem como do ataque de piratas, que saqueavam com freqüência os povoados do litoral brasileiro (PORTO DE SANTOS, 2005c).

A administração e a realização das atividades portuárias no Brasil sempre foram responsabilidade do Estado. A baixa competição interna entre terminais de contêineres dos por- tos brasileiros somada aos baixos investimentos do governo em infra-estrutura e modernização dos portos resultaram numa fraca produtividade e eficiência, se comparados ao cenário mundial (BNDES, 2000).

Entretanto, a partir de 1993, com a lei 8.630, de Modernização dos Portos, as atividades portuárias brasileiras sofreram grandes modificações. O objetivo dessa lei foi tornar o transporte marítimo e sua cadeia de negócio um processo mais competitivo, de forma a aprimorar o comércio exterior (BNDES, 2000). Como reflexos dela, a operação portuária brasileira vem sendo transferida para o setor privado mediante arrendamento de áreas operacionais (Figura 7) associado a programas de meta em busca de investimentos, produtividade e competitividade. Ao Estado continuam cabendo as funções de administrador portuário (BNDES, 2001).

As grandes concessões para iniciativas privadas ocorreram, no entanto, a partir de 1998. Desde então os investimentos vêm sendo voltados para a melhoria da eficiência operacional dos portos, como ampliação da área de atracação, construção de berços, compra de máquinas (porteiners, transteiners, etc.), aumento da profundidade de calados, entre outros. São investimentos altos e inéditos na indústria portuária brasileira. Com o advento da iniciativa privada, a operação portuária tornou-se mais competitiva, uma vez

\section{Movimentação de cargas (milhões ton.)}

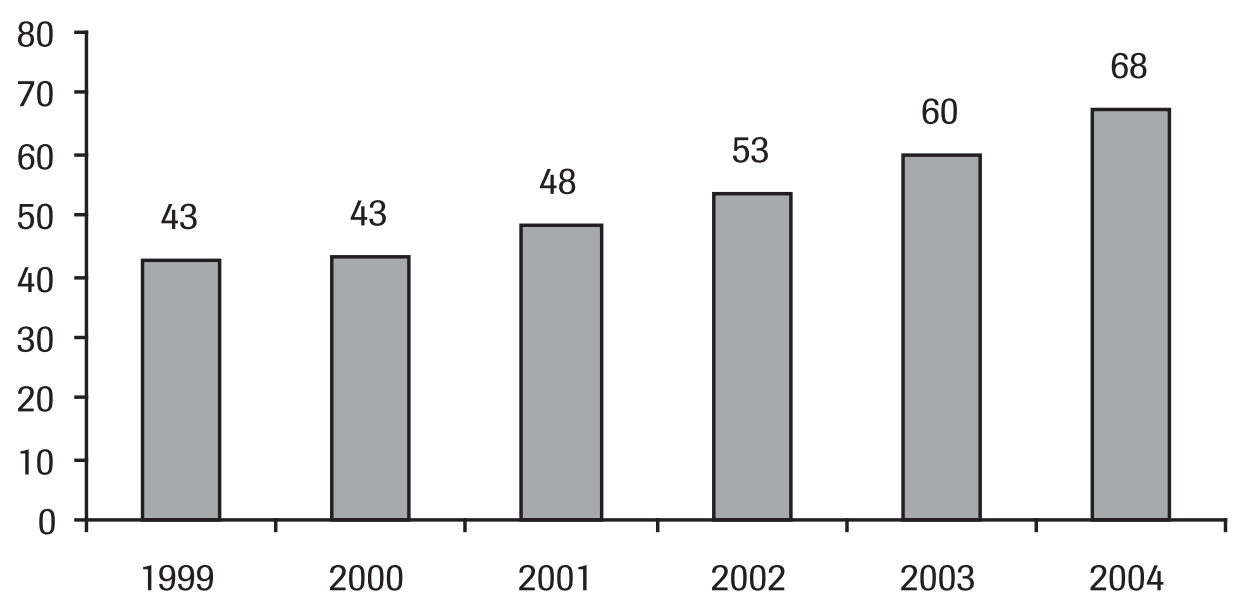

Figura 6: Série histórica da movimentação do porto de Santos

Fonte: Porto de Santos, 2005b. 
que um mesmo porto possui diversas empresas operando em diferentes terminais portuários.

O programa de arrendamentos e parcerias (Proaps) também contribuiu para impulsionar a presença da iniciativa privada no porto de Santos. Após sua implantação em 2003, 24 novas áreas foram arrendadas e 27 estão em licitação (PORTO DE SANTOS, 2005d). Para garantir a expansão do porto de Santos e o aumento de sua eficiência, diversas obras estão sendo conduzidas pela Companhia Docas de Santos (PORTO DE SANTOS, 2005f).

Os agentes que compõem a cadeia de valor dos terminais de contêineres podem ser divididos em:

- armadores ou agentes marítimos - efetuam o transporte marítimo de cargas;

- exportadores - exportam cargas para o exterior;

- importadores - importam cargas do exterior;
- agentes consolidadores (Non-Vessel Operating Common Carrier - NVOCC) - locam contêineres no navio para poderem revender para clientes que não têm demanda suficiente para contratar um contêiner inteiro;

- transportadores ou operadores logísticos - transportam cargas do porto à empresa exportadora ou importadora; $\mathrm{e}$

- terminais de contêineres - operam as cargas, descargas e armazenamentos.

Há também agentes secundários que apóiam o processo:

- despachantes - efetuam o despacho aduaneiro da carteira de clientes;

- governo - alfândegas, Receita e Polícia Federal, fiscalizam o processo e taxam as cargas; e

- seguradoras - disponibilizam seguro das cargas transportadas.

\section{Evolução dos arrendamentos no porto de Santos}

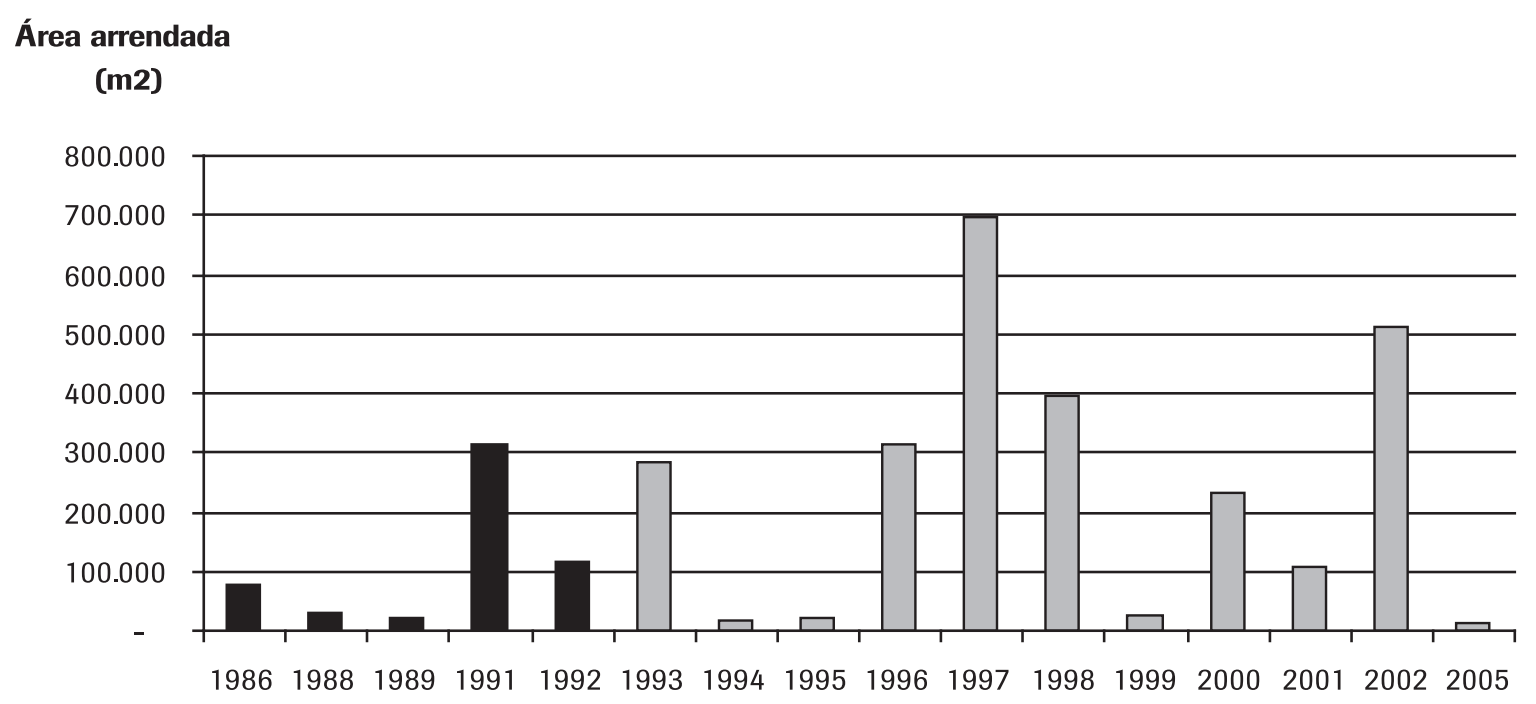

Contratos firmados após a lei 8.630

Contratos firmados antes da lei 8.630

Figura 7: Arrendamento das áreas do porto de Santos

Fonte: Porto de Santos, 2005e. 
Dependendo do sentido, a cadeia de valor pode assumir várias formas, uma vez que a origem da carga pode ser do exportador ou do importador; da verticalização. Em alguns casos, a empresa transporta a própria carga até o porto. Dependendo de condições estruturais, há casos, no exterior, em que a indústria fica instalada no próprio porto; em outros, o produto é elaborado no próprio navio, como a indústria pesqueira. É o caso da cadeia a seguir, considerando que o importador é o cliente final (Figura 8).
No contexto digital, uma iniciativa que tem contribuído para conectar os agentes do porto de Santos é o projeto supervias do porto. Trata-se de uma grande rede de informações que mantém em contacto autoridades portuária, marítima e alfandegária, operadores portuários, agentes de navegação e práticos. As supervias contemplam hoje três sistemas (PORTO DE SANTOS, 2005g).

- Atracação - permite aos usuários do porto requisitarem a atracação. Uma das facilidades bem recebidas pelos agentes são as informações que eles devem fornecer à Codesp, ao requisitarem atracação: comprimento do navio, boca (largura), calado, bandeira, data de construção, estaleiro e vários outros dados básicos sobre a embarcação. Hoje, basta escrever no computador o

Apesar da mencionada evolução da eficiência no porto de Santos, os terminais de contêineres brasileiros ainda possuem importantes restrições para a conquista de um patamar competitivo à altura dos padrões internacionais. Um dos principais fatores que influenciam o custo final das operações de terminais de contêineres é a mão-de-obra utilizada na operação. De acordo com a legislação brasileira, um órgão regulador, o Ogmo, Órgão gestor de mão-de-obra, é responsável por determinar a quantidade de trabalhadores que os operadores portuários utilizarão na movimentação de contêineres entre os terminais e os navios (BUSSINGER, 1998). Em virtude das questões sociais do país e da força política dos sindicatos, essa determinação é constantemente superestimada pelo órgão, o que gera custos excessivamente altos para as empresas brasileiras.

De acordo com a empresa analisada, um terminal eficiente opera com cerca de 20 estivadores por turno de trabalho, ao passo que no porto de Santos esse número sobe para até 60 trabalhadores. A participação da mão-de-obra nos custos da operação chega a 40\%. Resultado: a eficiência operacional deixa de constituir uma vantagem competitiva sustentável. Caracteriza-se então, um cenário propício à customização dos serviços e à integração da cadeia como ferramentas para diferenciação competitiva. nome do navio, que surgem imediatamente na tela todas essas informações contidas no Lloyd's Register, anuário britânico que publica os dados das embarcações mercantes. São dados automaticamente transcritos na requisição de atracação e prioridade (RAP), aos quais os agentes acrescentam outras informações: hora de chegada do navio à barra, calado máximo, produto movimentado e operação de carga ou descarga (A TRIBUNA, 2001).

- Manifesto - permite às agências e armadores enviarem manifestos, documentos que reúnem e são enviados direta, eletrônica e detalhadamente com toda a programação de cargas do navio, de exportação e importação, às autoridades alfandegária e portuária.

- Boletim de descarga e embarque - possibilita aos operatoridades alfandegária, portuária e ao Ogmo. Antes, esses boletins eram documentos preenchidos a mão, na faixa do cais, por conferentes que discriminavam as mercadorias de descarga e embarque.

Além do projeto supervias, a companhia Docas de Santos disponibiliza um site na Internet com informações atualizadas diariamente sobre navios atracados, atracações programadas e condições climáticas. dores enviarem direta e eletronicamente os boletins às au-

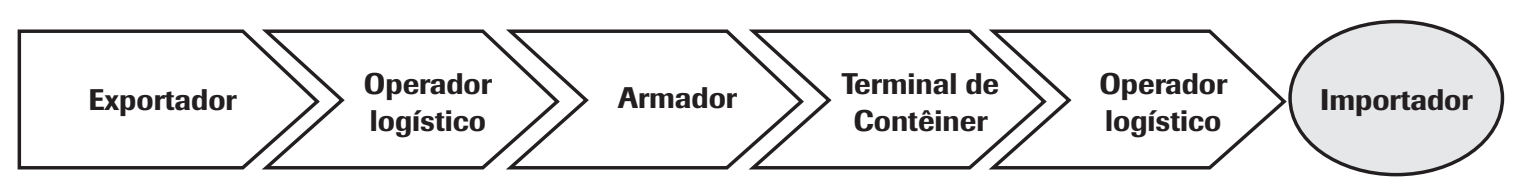

Figura 8: Cadeia de valor da operação portuária com importador na ponta final 


\subsection{A empresa}

O operador portuário analisado foi criado a partir do consórcio que venceu o leilão de privatização de um dos terminais de contêineres de Santos, realizado na Bolsa de Valores de São Paulo. Os investimentos para modernização da estrutura para compra de equipamentos de última geração para carga, descarga e movimentação de contêineres chegaram a US\$ 150 milhões nos três anos após a privatização.

O objetivo da empresa é ser o maior terminal de contêineres da América Latina e sua finalidade é oferecer serviços de operação portuária com padrão de qualidade reconhecido pelo mercado. São fatores críticos de sucesso identificados:

- estreitar o relacionamento com os agentes da cadeia;

- reduzir custos operacionais;

- aperfeiçoar os processos logísticos;

- aumentar a participação no mercado; e

- aumentar a retenção de cargas.

Uma orientação estratégica para atingir esses objetivos é privilegiar o cliente, o que representa uma transição para a empresa que muitas vezes privilegiou a carga, controlando a movimentação dos contêineres, sem fornecer a visão integrada das cargas de determinado cliente.

Outra diretriz é a parceria com empresas multimodais, viabilizando assim o conceito de one-stop-shopping, ou seja, oferecendo ao cliente todos os serviços logísticos necessários. Essa diretriz se vale da condição do porto de Santos ser um local que facilita a intermodalidade, uma vez a 65 quilômetros de São Paulo, servido por grande complexo de transporte (Figura 9), e dos dois aeroportos num raio de 100 quilômetros (PORTO DE SANTOS, 2005h).

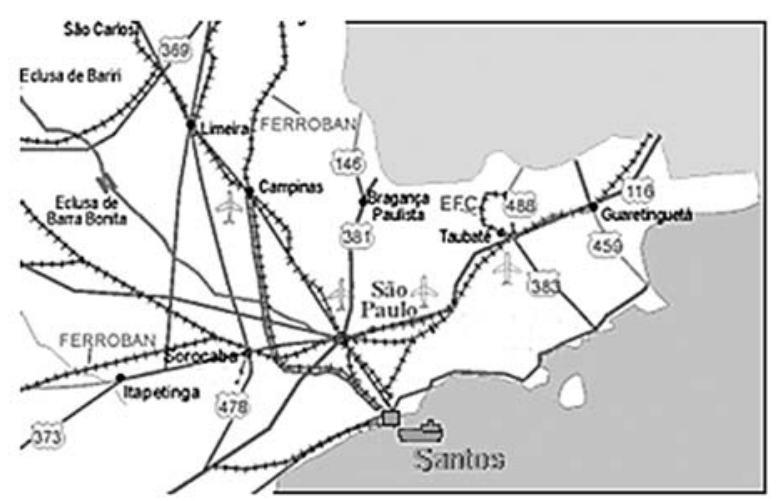

Figura 9: Complexo de transporte do Porto de Santos Fonte: Porto de Santos 2005h.

Os serviços de contêineres prestados pelo terminal a seus clientes são diversificados. Os negócios de maior faturamen- to são as operações portuárias e a armazenagem de carga.

- Armazenamento - contêiner ou carga solta

- Desembaraço aduaneiro

- Estufagem de contêineres

- Entrega de contêineres

- Operação portuária - carga e descarga de mercadorias

- Reembalagem

- Retirada de contêineres vazios do terminal

- Serviços de paletização

- Transporte multimodal

Os concorrentes diretos da empresa são os outros operadores portuários do porto de Santos e os indiretos são os terminais retro-alfandegários (TRAs), sem infra-estrutura para atracação, portos secos localizados no interior - em São José do Rio Preto, SP - e outros portos nacionais e internacionais.

A empresa julga que seus diferenciais frente à concorrência são a multimodalidade, a dimensão de seu terminal, a linha azul - modalidade em que a alfândega se compromete a liberar a carga em até quatro horas -, a infra-estrutura de movimentação, a armazenagem e a qualidade na prestação de serviços.

A comunicação com os clientes é mantida por centrais de atendimento por telefone, pela Internet, bem como pela presença dos próprios vendedores. Entre os serviços prestados estão o pedido de vistoria, a solução e o acompanhamento de problemas operacionais do cliente, a resposta e o encaminhamento dos e-mails do site e o cálculo de armazenagem.

\subsection{0 papel da $\mathrm{TI}$}

Antes da privatização da empresa havia vários sistemas com bancos de dados descentralizados. Com a aquisição do terminal, todos os sistemas foram migrados para rodar numa mesma base de dados cujas adaptações e melhorias continuam ocorrendo. As principais aplicações de TI são as seguintes.

- Base de dados de clientes - base de dados em processo de unificação de cadastros dos clientes dos vários sistemas, se bem que ainda contém redundâncias que estão sendo corrigidas, por exemplo, falta unificar as diversas interfaces desses dados.

- Sistema de gestão de terminal alfandegário, SGTA - apoio ao controle de cargas de importação, contém informações sobre as mercadorias e mantém comunicação de dados com a alfândega via EDI.

- Container Terminal Information System, CTIS - apóia o controle de exportação, embarque e descarga do navio, yard control (controle de pátio) e interage com o ship planning, planejador de alocação da carga no navio. O sistema segue o padrão mundial de transmissão de arquivos via EDI. 
- Sistema de faturamento - emite fatura das movimentações operacionais do SGTAP e do CTIS.

- Financeiro - controla contas a pagar e a receber e emite relatório financeiro.

- Sistema de atendimento ao cliente, SAC - armazena ocorrências, envia mensagens para envolvidos e agenda compromissos.

- Aplicações de Internet - visam à integração dos agentes da cadeia pelo portal da empresa, que oferecerá uma proposta de valor para cada tipo de empresa que visita o portal.

A empresa pode ser considerada usuária de informação intensiva segundo a matriz de intensidade de informação (PORTER; MILLAR, 1985), uma vez que seu processo e serviço oferecido possuem alta quantidade de informação, isto é, dependem de muitas informações para o processo ser executado e o serviço prestado proporciona muita informação ao usuário. O processo logístico compreende uma série de informações cruciais para o sucesso da operação, como origem, destino, melhores rotas, data de embarque e desembarque, cuidados a serem tomados com a carga, etc. O serviço oferecido, por sua vez, pode ser considerado parte movimentação de carga e parte informação, como o tracking da carga, informações sobre o despacho do produto, entre outras.

Nesta perspectiva, a empresa viabiliza sua estratégia de negócios através de uma nova estratégia de TI, buscando liderança tecnológica, isto é, busca de uso inovador da tecnologia com fins estratégicos.

\subsection{Estratégia on-line}

A empresa pretende que sua presença on-line, que compreende o conjunto portal, aplicações de Internet e ferramentas de comunicação com o cliente on-line, atenda a determinados requerimentos. Considerando os fatores críticos de sucesso expostos no item 4.2, foram relacionadas as expectativas da empresa com a Internet aos seus objetivos de negócios (Tabela 3).

A nova estratégia de presença da empresa analisada na Internet requer a formação de uma rede de valor (BOVET; MARTHA, 2001) no segmento portuário, rede essa que deverá estar alinhada com as expectativas da empresa pela presença on-line, contribuindo assim para que os objetivos de negócios sejam alcançados.

A Internet pareceu ser uma plataforma ideal para a implementação da rede de valor, uma vez que permite um desenvolvimento escalonável com menores esforços para padronização dos protocolos de comunicação entre os agentes envolvidos e mais rapidez de implantação. Além de flexível e de promover melhor integração entre os parceiros, a rede de valor aplicada é altamente aderente às orientações estratégicas da empresa (Figura 10). Cada agente da rede tem uma proposta de valor distinta, que atende as aplicações on-line específicas (Tabela 4).

Para criar aplicações que

Apesar da grande importância da informação no processo, as aplicações de TI estão em transição, passando de aplicações isoladas, que atendiam a cada departamento isoladamente, para aplicações integradas de valor estratégico, que compreendem serviços on-line de atendimento ao cliente, que serão discutidos posteriormente. Por isso, pode-se considerar que a empresa situa-se numa posição de transição, de acordo com o grid estratégico de McFarlan (1984).

A empresa procura, mediante suas novas aplicações de TI, um posicionamento diferenciado graças a uma abordagem voltada para o cliente, uma de suas diretrizes estratégicas. Portanto, pode-se dizer que, de acordo com o modelo de Henderson \& Venkatraman (1993), a empresa adota a perspectiva de transformação tecnológica:

Estratégia de negócios $=>$ Estratégia de TI $=>$ Estrutura de TI suportassem a rede de valor, a empresa promoveu uma série de modificações em seu portal. O departamento de $e$-business liderou a transição entre o site antigo e o novo portal, cujo modelo de negócios está descrito no Anexo A. Esse departamento está vinculado à diretoria de marketing, o que facilitou o alinhamento com a estratégia de negócios da empresa, embora prejudicasse um pouco a integração com a área de TI, que planejava os recursos e discutia a viabilidade das funcionalidades para depois de concluída a estratégia on-line.

Ao iniciar essas alterações, o site oferecia informações segmentadas para cada agente, entretanto, o grau de personalização era superficial. Havia pouco conteúdo on-line e não se divulgavam todos os produtos e serviços da empresa. A consulta a cargas em movimentação era feita por contêineres, o que evidenciava a falta de foco no cliente, uma vez que não havia uma consolidação das cargas por cliente. 
Outro aspecto que evidenciava a falta de foco no cliente era a falta de cuidado com o design do site. As imagens e as cores não promoviam os serviços e a marca da empresa, bem como ele carecia de um planejamento de como as informações seriam dispostas para facilitar a navegação do usuário. Havia necessidade da utilização da barra de scroll

Tabela 3: Fatores Críticos de Sucesso e expectativas da presença on-line

\begin{tabular}{|c|c|}
\hline Fatores críticos de sucesso & Expectativas da presença on-line \\
\hline $\begin{array}{l}\text { Estreitar o relacionamento com os } \\
\text { agentes da cadeia }\end{array}$ & $\begin{array}{l}\text { - Prover canal de auto-atendimento aos clientes para que eles tenham acesso rápido às } \\
\text { informações de serviços e de suas cargas } \\
\text { - Oferecer comunicação diferenciada para cada agente da cadeia } \\
\text { - Aumentar a segurança e a confiabilidade das informações prestadas aos clientes } \\
\text { - Gerar banco de dados de clientes e prospects por meio de cadastros na Internet, banco } \\
\text { esse que deve ser qualificado com informações tais como origem do cliente, possibilidades } \\
\text { de negócios, etc. } \\
\text { - Integrar informações de todos os agentes para agilizar o trâmite burocrático - despacho, } \\
\text { documentação para embarque/desembarque da carga, câmbio, etc. }\end{array}$ \\
\hline Reduzir custos operacionais & $\begin{array}{l}\text { - Diminuir chamadas ao serviço de atendimento ao cliente, SAC } \\
\text { - Contratação e pagamento de serviço via portal } \\
\text { - Aumento da eficiência dos processos da empresa }\end{array}$ \\
\hline Aperfeiçoar os processos logísticos & $\begin{array}{l}\text { - Exibir lista de agências marítimas preferenciais - que já possuem integração com processos } \\
\text { da empresa } \\
\text { - Para evitar esperas por falta de documentos, prover informação sobre a documentação } \\
\text { necessária para cada etapa do embarque e desembarque } \\
\text { - Exibir posição de movimentação das cargas (tracking) incluindo imagens das operações } \\
\text { (webcans) }\end{array}$ \\
\hline Aumentar a participação no mercado & $\begin{array}{l}\text { - Reforçar o portfolio de serviços, agregando funcionalidades on-line } \\
\text { - Exibir lista de rotas. } \\
\text { - Expandir presença on-line para sites de armadores } \\
\text { - Expor projetos de expansão } \\
\text { - Divulgar produtos e serviços }\end{array}$ \\
\hline
\end{tabular}

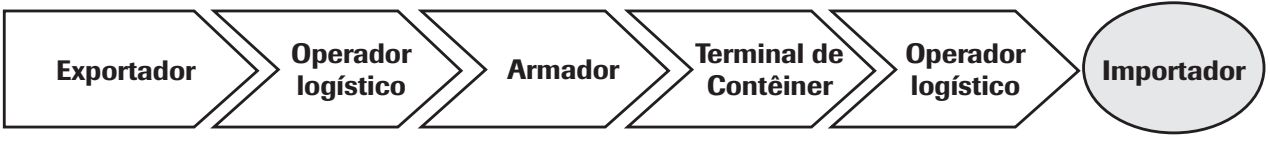

Rede de Valor Proposta

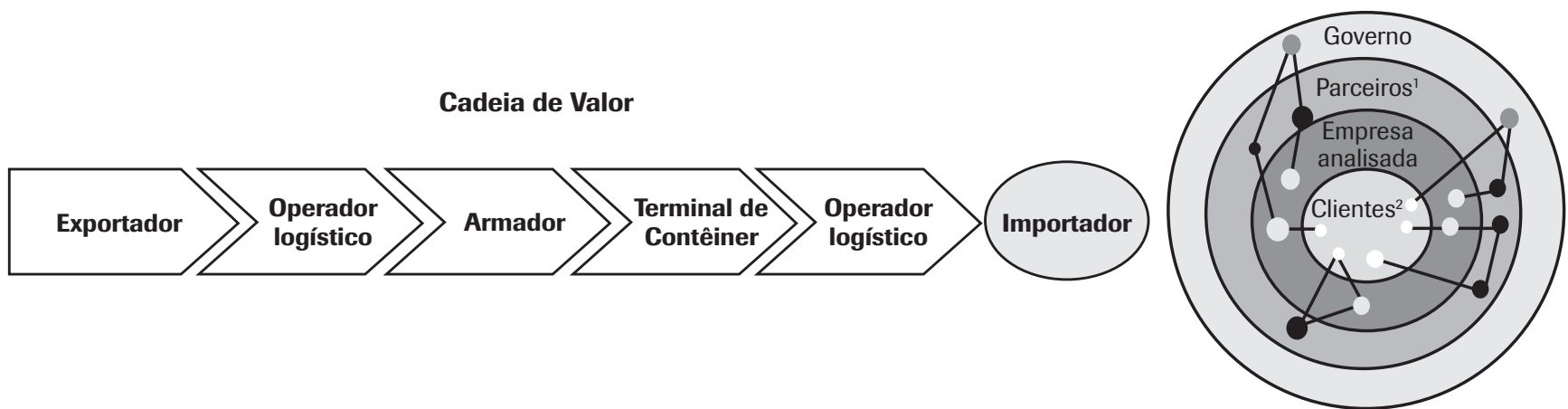

(1) Operadores Logísticos, Transportadoras

(2) Importadores, Exportadores, Armadores, Despachantes, NVOCCS

Figura 10: Cadeia de valor tradicional versus rede de valor no Porto de Santos 
vertical (rolamento de página) para que todas as informações da página fossem visualizadas. Os itens do menu não eram claros para o usuário - em vez de utilizar o "quem somos" para mostrar informações corporativas, o site mostrava a razão social da empresa -, bem como não havia ferramentas para auxiliar a interação do usuário, como busca, mapa do site e perguntas mais freqüentes.

\section{essalte-se que é essencial que se mantenha a visão estratégica, evitando assim movimentos precipitados que podem reduzir lucratividade da indústria.}

er influenciado nesse resultado, uma vez que ela agregou diferenciais, como pode ser observado na Tabela 5, que compara a presença on-line do terminal analisado com seus principais concorrentes.

A empresa promoveu inovação na indústria portuária brasileira ao ser pioneira na integração de todos os agentes da cadeia pela Internet, assim como conseguiu obter diferencial competitivo na Internet, ao oferecer funcionalidades on-line que não são ofertadas por seus principais concorrentes em termos de faturamento (Tabela 5).

\subsection{Indicadores da presença}

Ao desenvolver a rede de valor na Internet, a empresa procurou alcançar os objetivos de negócios mencionados anteriormente e obter um diferencial em face dos concorrentes. A empresa conseguiu aumentar sua participação no mercado, uma vez que seu faturamento cresceu $26 \%$ entre os anos de 2003 e 2004 . Vários investimentos contribuíram para esse incremento, como marketing, novos serviços, aumento da capacidade do terminal, entre outros. A Internet pode

\section{CONCLUSÃO}

O terminal portuário aumentou expressivamente seu faturamento, resultado de uma série de fatores, mas que também pode ser creditado à estratégia on-line. A integração da cadeia promovida pela cadeia de valor (BOVET; MARTHA, 2001) foi inédita no segmento. Além disso, a empresa conseguiu oferecer funcionalidades exclusivas em seu portal (Tabela 5) estabelecendo uma vantagem

Tabela 4: Integração e criação de valor para os diferentes agentes do sistema portuário

\begin{tabular}{|c|c|c|}
\hline Agentes & Proposta de valor & Exemplos de aplicações on-line \\
\hline $\begin{array}{l}\text { Importadores e } \\
\text { exportadores }\end{array}$ & $\begin{array}{l}\text { Ser o parceiro que, mediante uma relação } \\
\text { transparente, ofereça total conhecimento } \\
\text { e controle das operações a importadores } \\
\text { e exportadores }\end{array}$ & $\begin{array}{l}\text { Contratação e pagamento on-line dos serviços } \\
\text { Canal de auto-atendimento para consulta de situação da carga } \\
\text { Histórico de operações } \\
\text { Simulador de tributação }\end{array}$ \\
\hline Armadores & $\begin{array}{l}\text { Ser o parceiro que disponibilize, além } \\
\text { de agilidade e eficiência operacional, } \\
\text { confiabilidade e rapidez nas informações } \\
\text { trocadas }\end{array}$ & $\begin{array}{l}\text { Booking } \\
\text { Relatórios gerenciais } \\
\text { Pagamento on-line da fatura }\end{array}$ \\
\hline Transportadoras & $\begin{array}{l}\text { Ser o parceiro que garanta rapidez, } \\
\text { agilidade e conveniência na sua prestação } \\
\text { de serviços por intermédio da troca mútua } \\
\text { de informações numa relação interativa }\end{array}$ & $\begin{array}{l}\text { Webgate - portão exclusivo no terminal, sem as filas } \\
\text { rotineiras, para transportadoras que agendarem pela Internet } \\
\text { suas entregas e retiradas de carga } \\
\text { Informações da carga a ser carregada e descarregada }\end{array}$ \\
\hline Prospects & $\begin{array}{l}\text { Ser a empresa que forneça informações } \\
\text { e ferramentas de subsídio para escolha e } \\
\text { contratação do operador portuário }\end{array}$ & $\begin{array}{l}\text { Simulador de tributação } \\
\text { Simulador de contratação de serviços }\end{array}$ \\
\hline Governo/Alfândega & $\begin{array}{l}\text { Ser a empresa que forneça informações } \\
\text { e serviços para auxílio do trabalho da } \\
\text { Alfândega }\end{array}$ & $\begin{array}{l}\text { Informações sobre os contêineres importação/exportação, } \\
\text { Agendamento de inspeção - preparação e posicionamento } \\
\text { de contêiner } \\
\text { Informações da carga da União no armazém }\end{array}$ \\
\hline
\end{tabular}


Tabela 5: Funcionalidades on-line do terminal analisado versus concorrência

\begin{tabular}{|c|c|c|c|}
\hline Funcionalidades & Terminal analisado & Concorrente A & Concorrente B \\
\hline Informações sobre produtos e serviços & $\mathrm{x}$ & $x$ & $x$ \\
\hline Simulador de contratação de serviços & $\mathrm{X}$ & & \\
\hline Contratação on-line dos serviços & $x$ & & \\
\hline Lista de atracação & $\mathrm{x}$ & & $\mathrm{x}$ \\
\hline Presença de carga & $x$ & & $\mathrm{X}$ \\
\hline Histórico de operações & $x$ & $\mathrm{X}$ & \\
\hline Simulador de tributação & $\mathrm{x}$ & & \\
\hline Pagamento on-line da fatura & $x$ & & \\
\hline Agendamento de operações & $x$ & $x$ & \\
\hline Webgate para transportadoras & $x$ & & \\
\hline Rastreamento da carga & $x$ & $x$ & $\mathrm{x}$ \\
\hline Área para governo/alfândega & $x$ & & \\
\hline
\end{tabular}

Legenda: $\mathrm{X}$ - a empresa disponibiliza a funcionalidade na Internet.

Fonte: baseado em visitas aos sites de cada empresa.

competitiva. O caso parece corroborar com a visão de Farrell (2003), que afirma que o uso da TI associado a mudanças nos processos tem potencial para gerar vantagens competitivas.

Contudo, deve-se ressaltar a importância da manutenção de um controle no âmbito estratégico, que permitirá à empresa proteger sua fonte de lucro por mais tempo através de manutenção de seus serviços essenciais (potencializando sua diferenciação de serviços) e o oferecimento de soluções inovadoras e pioneiras (via convergência de negócios das atividades fins dos clientes).

O caso analisado mostrou que a obtenção de vantagem competitiva com utilização da Internet é possível, desde que haja uma abordagem estratégica estruturada, um forte planejamento, um certo arrojo para "reinventar o futuro" e que se estabeleçam parcerias baseadas em forte conhecimento do cliente. Ressalte-se que é essencial que se mantenha a visão estratégica, evitando assim movimentos precipitados que podem reduzir a lucratividade da indústria.

Percebeu-se a influência das características da economia brasileira. O fato de o mercado portuário ter sido recém-privatizado provocou atraso tecnológico, o que gerou oportunidade para que o terminal analisado oferecesse integração num segmento que tradicionalmente fazia pouco uso de aplicações de TI, em especial para interconexão entre as empresas.

O presente trabalho ensejou um melhor conhecimento do papel da Internet em cadeias de suprimento de grande impacto na economia. Vislumbra-se, pois, o prosseguimento de pesquisas que aprofundem tal discussão.

\section{Artigo recebido em 03/02/2004 Aprovado para publicação em 05/08/2008}




\section{REFERÊNCIAS}

A TRIBUNA. Codesp inaugura sistema eletrônico para atracação. A Tribuna - Porto e Mar, edição de 24 de abril, p. C5, 2001

A TRIBUNA. Movimento de cargas no porto bate recorde. Disponível em www.atribuna.com. br, site acessado em abril, 2003.

BENBASAT, D.K. GOLDSTEIN, M. MEAD. The case research strategy in studies of information systems. MIS Quarterly, v. 11, n. 3, p. 369-386, 1987.

BNDES - Cadernos de Infra-estrutura - Banco Nacional de Desenvolvimento. Disponível em em www.bndes.gov.br, site acessado em abril 2003, 2001.

BNDES- Informe Infra-estrutura - Porto de Santos: Aspectos de competitividade. Disponível em www.bndes.gov.br, site acessado em abril 2003, 2000.

BOVET, D.; MARTHA, J. Redes de ValorAumente os lucros pelo uso da Tecnologia da Informação na cadeia de valor. São Paulo: Negócio Editora Ltda., 2001.

BUSSINGER, F. Reformas e regulação portuária. Pesquisa IPEA, 1998.

CARVALHO, M. M.; LAURINDO, F. J. B. Estratégias para Competitividade. São Paulo: Editora Futura, 272 p., 2003.

CARVALHO, M. M.; LAURINDO, F. J. B.; PESSÔA, M. S. P. Information Technology Project management to achieve efficiency in Brazilian Companies. In: KAMEL, Sherif. (Org.). Managing Globally with Information Technology. Hershey, p. 260-271, 2003.

CHANDRASHEKAR, A.; SCHARY, P. B. Toward the Virtual Supply Chain: the convergence of IT and Organization. International Journal od Logisitics Management, v. 10, n. 2, p. 27-39, 1999.

CLAVER, E.; GONZALEZ, R.; LLOPIS, J. An analysis of research in information systems (1981-1997). Information \& Management, v. 37, n. 4, p. 181-195, 2000.
DUHAN S.; LEVY M.; POWELL P. Information systems strategies in knowledge-based SMEs: the role of core competencies. European Journal of Information Systems, v. 10, p. 25-40, 2001.

EVANS, P. B.; WURSTER, T. S. Strategy and the New Economy of Information. Harvard Business Review, v. 75, p. 71-82, 1997.

FARRELL, D. The Real New Economy. Harvard Business Review, v. 81 , n. 10, p. 104-112, 2003.

HENDERSON, J. C.; VENKATRAMAN, N. Strategic alignment: leveraging information technology for transforming onganizations. IBM Systems Journal, v. 32, n. 1, p. 4-16, 1993.

GAZETA MERCANTIL, Porto de Santos se prepara para novo salto em 2005. Gazeta Mercantil - Transportes, edição de 10 de janeiro de 2005, p. A-12, 2005

LAURINDO, F. J. B.; CARVALHO, M. M.; SHIMIZU, T. Information Technology Strategy Alignment: Brazilian Cases. In: KANGAS, Kalle. (Org.). Business Strategies for Information Technology Management. Hershey, p. 186-199, 2003.

LAURINDO, F. J. B. Tecnologia da Informação: eficácia nas organizações. São Paulo, Editora Futura, 2002, $248 \mathrm{p}$.

LAURINDO, F. J. B. Tecnologia da Informação como Suporte às Estratégias Empresariais. In: AMATO NETO, João. (Org.). Redes entre organizações. São Paulo, 2005, p. 240-257.

LEONARD-BARTON, D., A dual methodology for case studies: synergistic use of longitudinal single site with replicated multiple sites. Organization Science, v. 1, n. 3, p. 248-266 1990.

MATTOS, C. A.; LAURINDO, F. J. B. New Products Development Based on Web Technology: Case Studies in Brazilian Companies. Brazilian Journal of Operations and Production Management, v. 4, p. 61-76, 2007

MC FARLAN, W. F. Information technology changes the way you compete. Harvard Business Review, v. 62, n. 3, p. 98-103, 1984.
MIGUEL, P. A. C. Estudo de caso na engenharia de produção: estruturação e recomendações para sua condução. Revista Produção, v. 17, n. 1, p. 216-229, 2007.

OLIVEIRA, C. L. O.; LAURINDO, F. J. B. CARVALHO, M. M.; SILVA, F. V. M., Integrating the Value System with the Internet: the Case of a Brazilian Harbour EuromaPoms. In: EUROMA\&POMS - European Operations Management Association \& Production and Operations Management Society - First Joint International Conference, 2003, Cernobbio. Procedings of EurOMA\&POMS2003 - One world? One view of OM? The challenges of integrating research and practices, v. 3 , p. 207-216, 2003.

PEREIRA, N. N.; LAURINDO, F. J. B. A importância da Tecnologia da informação na indústria de construção naval: Um estudo de caso. Revista Produção, v. 17, n. 2, p. 354-367, 2007.

PORTER, M. E. How Competitive forces shape strategy. Harvard Business Review, v. 57, n. 6, p. 137-145, 1979.

PORTER, M. E. Strategy and the internet. Harvard Business Review, v. 79, n. 3, p. 63-78, 2001.

PORTER, M. E.; MILLAR, V. E. How information gives you competitive advantage. Harvard Business Review, v. 63, n. 4, p. 149-160, 1985.

PORTO DE SANTOS (2005a). Santos e seu mercado, o grande porto do Brasil. www. portodesantos.com.br, acessado em fevereiro de 2005.

(2005b). Santos e suas características, série histórica de movimentação. www. portodesantos.com.br, acessado em fevereiro de 2005.

(2005c). História do Porto de Santos. www.portodesantos.com.br, acessado em fevereiro de 2005.

(2005d). Santos e seus mercados, as oportunidades. www.portodesantos. com.br, acessado em fevereiro de 2005. 
(2005e). Santos e suas características, áreas arrendadas. www.portodesantos. com.br, acessado em fevereiro de 2005.

(2005f). Projetos de infra-estrutura. www.portodesantos.com.br, acessado em fevereiro de 2005.

(2005g). Supervia de Informações no Porto de Santos. www.portodesantos.com. br, acessado em fevereiro de 2005.

(2005h). Santos e seus mercados, facilidade e acessos. www.portodesantos. com.br, acessado em fevereiro de 2005.
PRAHALAD, C. K.; RAMASWAMY, V. Co-opting Customer Competence. Harvard Business Review, v. 78, n. 1, p. 79-87, 2000.

RAYPORT, J. F.; SVIOKLA, J. J. Exploiting the Virtual Value Chain. Harvard Business Review, v. 73, n. 6, p. 75-85, 1995.

ROCKART, J. F. Chief executives define their own data needs. Harvard Business Review, v. 57, n. 2, p. 81-92, 1979.

SOUZA, C. R. Porto de Santos fecha 2004 com maior crescimento em dez anos. www. portodesantos.com.br, acessado em fevereiro de 2005, 2005

TAPSCOTT, D. Rethinking Strategy in a Networked World (or how Michael Porter is wrong about the Internet). Strategy + Business, issue 24, 8 p., 2001.

YIN, R. K. Case Study Research: Design and Methods. Newbury Park, Rev. ed. Sage Publications, 1991.

ZWASS, V. Foundation of Information Systems Boston: Irwin McGraw-Hill, 1998.

\section{SOBRE OS AUTORES}

\section{Claudio Luis Cruz de Oliveira}

Escola Politécnica da Universidade de São Paulo

End.: Av. Prof. Almeida Prado, 128 Tr.2 Biênio 2o andar - São Paulo - SP - Brasil - CEP 05508-900

Tel: 55 (11) 3091-5363

E-mail: claudio_oliv@hotmail.com

\section{Fernando José Barbin Laurindo}

Depto. de Engenharia de Produção

Escola Politécnica da Universidade de São Paulo

End.: Av. Prof. Almeida Prado, 128 Tr.2 Biênio 2o andar - São Paulo - SP - Brasil - CEP 05508-900

Tel: 55 (11) 3091-5363

E-mail: fjblau@usp.br

\section{Marly Monteiro de Carvalho}

Depto. de Engenharia de Produção

Escola Politécnica da Universidade de São Paulo

End.: Av. Prof. Almeida Prado, 128 Tr.2 Biênio 20 andar - São Paulo - SP - Brasil - CEP 05508-900

Tel: 55 (11) 3091-5363

E-mail:marlymc@usp.br

\section{Francisco de Vilhena Moraes Silva}

Agência NBS

End.: Rua Lauro Muller, 116, cj 3802 - Botafogo - Rio de Janeiro - Brasil - CEP 22290-160

Tel.: 55 (21) 2586-3131

E-mail: chicovilhena@yahoo.com 


\section{ANEXO 1 - ROTEIRO PARA O ESTUDO DE CASO}

\section{Passo 1: Descrição do mercado}

- Contexto da indústria

- Descrição do processo e de seus agentes

- Tamanho do mercado e evolução

- Riscos e oportunidades relacionados ao ambiente competitivo

- Características do mercado brasileiro que influenciam a competição na Internet (potencialidades e fragilidades)

- Penetração da Internet no segmento (quantas empresas / consumidores utilizam a tecnologia)

\section{Passo 2: Análise da empresa}

- Histórico

- Objetivos

- Fatores críticos de sucesso de Rockart (1979)

- Concorrência

- Estratégia de negócios

- Principais produtos e serviços

- Relacionamento através dos diversos canais com o cliente

\section{Passo 3: Papel da TI na empresa}

- Sistemas de informação da empresa e como estão estruturados

- Posicionamento na matriz de intensidade de informação de Porter e Millar (1985)

- Identificação do valor estratégico da TI no presente e no futuro através do grid estratégico (MCFARLAN, 1984)

- Esclarecimento da origem da estratégia de negócio e de TI através do modelo do alinhamento estratégico de Henderson e Venkatraman (1993)

\section{Passo 4: Caracterização do modelo de negócios on-line}

- Quais os objetivos da empresa com relação à utilização da Internet

- Qual a estratégia da empresa para alcançar estes objetivos

- Como a área de Internet está estruturada

- Qual o histórico das aplicações de Internet na empresa

- Quais as aplicações de Internet

\section{Passo 5: Indicadores da presença on-line}

- Quais as métricas para avaliar a eficiência e a eficácia da estratégia on-line

- Como essas métricas têm evoluído

- Quais os resultados gerais (incluindo os qualitativos) obtidos até o momento com a aplicação da estratégia on-line

- Comparação com dados da concorrência para avaliar se a utilização da Internet está gerando vantagem competitiva 